\title{
Awareness, Attitudes and Practices of women related to breast cancer in Niamey and Zinder
}

\author{
Abdou Aissami ( $\square$ aissamiabdou@gmail.com ) \\ Universiteit Antwerpen https://orcid.org/0000-0003-0105-6164 \\ Guido Van Hal \\ Universiteit Antwerpen \\ Dille Issimouha \\ SOS Cancer
}

Research article

Keywords: Breast cancer, awareness, women

Posted Date: November 12th, 2019

DOI: https://doi.org/10.21203/rs.2.17180/v1

License: (1) This work is licensed under a Creative Commons Attribution 4.0 International License.

Read Full License 


\section{Abstract}

Background: In Niger, breast cancer is the first cancer related morbidity and mortality within the female population. While Breast cancer awareness can contribute to early diagnosis and disease mortality reduction, Niger women's knowledge of breast cancer is not well documented. The objective of this study was to assess the knowledge, attitudes and practices of women related to breast cancer and have a look on the factors associated this knowledge.

Methods: The study was conducted thought a cross sectional survey in women population in Zinder and Niamey regions. A random sampling was used to select women in households within health districts. We defined a breast cancer knowledge score and used a generalized linear model to assess factors associated with breast cancer knowledge.

Results: A total of 675 women were included in the survey. Average age of women was 39.2 years (38.2$40.2)$ and $48.4 \%$ (44.7-52.2) of them were not educated. Overall women's knowledge of breast cancer is relatively low, only $41.2 \%$ (37.5-45.0) were aware of breast cancer. An area where women demonstrated an awareness was breast cancer symptoms knowledge with $65.0 \%$ (61.3-68.7). Insufficient level of knowledge was observed on knowledge of risk and protection factors with only $27.4 \%$ (24.0-31.0) level of awareness and breast cancer good practice with $16.9 \%$ (14.2-19.7). Younger age OR=0.98 (0.96-0.99) practicing clinical breast examination $\mathrm{OR}=2.25(1.31-3.16)$, breastfeeding $3.34(2.12-5.26)$, not having a history of participation to breast cancer $0.53(0.34-0.82)$ and living in rural and peri-urban areas 0.34 (0.20-0.44) were factors related to awareness of breast cancer.

Conclusion: Niger women had overall low level of breast cancer awareness. While they were not acquainted with breast self-examination and clinical breast examination, their knowledge of breast cancer symptoms was acceptable. Clinical breast examination, area of residence, age, breastfeeding and history of participation to breast cancer screening were found to be associated with breast cancer knowledge. Awareness programs can promote clinical breast examination as mammography is not common and target older women. Focus should be given to awareness of breast cancer risk factors and promoting early detection procedures.

\section{Background}

Breast cancer remains a public health concern worldwide including sub-Saharan African countries (Brinton et al.; 2014; Ferlay et al.; 2008). In Niger, breast cancer is identified as the first cause of cancer related morbidity and mortality standing for twenty-eight percent $(27.7 \%)$ of the overall cancer mortality within the female population, (WHO; Cancer Country Profiles 2014; Globocan; 2012, H. M. Zaki et al.; 2013, S Mamoudou et al.; 2013). Studies found that if women adopt early risk-reduction behaviours like physical activity, healthy diets, breastfeeding, non-extensive alcoholic beverage consumption to mention but a few, part of the breast cancer burden can be prevented through primary prevention (Colditz and Bohlke; 2014, Graham and Kari; 2015). This is even more important in countries like Niger where 
mammographic screening facilities are not widely available and research literature on breast cancer epidemiology and awareness is not extensive. Soliman, A. S., et al.; 2015 outlined younger age and late diagnosis are common features of breast cancer in Niger.

Knowledge of breast cancer among women is not generally high in sub Saharan Africa and not very well documented in Niger (Jennifer N. al.; 2017). Breast cancer awareness can significantly contribute to early diagnosis and disease mortality reduction (Anderson B \& Jakesz R 2008).

To the best of our knowledge, no recent studies were conducted in the analysis of knowledge, attitudes and practices of women related to breast cancer in Niger. The country does not yet have an operational cancer policy/strategy/action plan (WHO, Cancer Country Profiles, 2014). In this paper, we used and adapted Breast Cancer Awareness Measure, (BCAM) to asses knowledge and attitudes of women in Niamey and Zinder.

\section{Methods}

\section{1: Study design, sampling and data collection:}

The study targeted women aged from 25 and above in Niamey and Zinder regions to participate to the survey. The sampling frame was composed by a list of villages of the health districts and number of households in the two regions with a similar population of women at this age. A two-stage clustered random sampling was used to first select villages in health districts, then households within villages using random walk technique. Finally, women were randomly selected in these households as primary sampling units.

The required sample size is calculated based on a 95\% confidence interval, assuming that $50 \%$ of women know basics of breast cancer with a correction of design effect for cluster. We assume an average number of 7 persons per household (national institute of statistics reference from the last 2012 population Census). This gives us about 630 women we adjusted with a 5\% increase as a security margin to account for non-response. The collected data was analyzed using R version 3.4.0 Epidata analysis v2.2.2.183 and IBM SPSS Statistics 24. All confidence intervals were computed with 5\% error margin. The questionnaires were conducted using face to face interviews with women randomly selected in their households.

The aim of the study was to assess the knowledge, attitudes and practices of women related to breast cancer and have a look on the factors associated this knowledge. 


\section{2: Knowledge score construction}

We constructed a knowledge score variable for each respondent woman to assess an overall answer and estimate her level of knowledge and breast cancer awareness. This was done using the WHO breast cancer rating scale (https://www.ncbi.nlm.nih.gov/pmc/articles/PMC1514477/). We selected main factors associated with breast cancer like family history, maternity, breastfeeding and age. A scan of risk factors, protective factors, symptoms and warning signs was conducted to complete the BCAM items on symptoms and risk/protective factors.

A Weighting of the knowledge factors was done to substantiate and allow some leverage for important risk factors generally accepted (WHO) but also accounting for context specific factors. Globally, correct answers were given points (see table 1 below) and a wrong answer was given zero. Mammography is not that much common in Niger context (as of January 2018, the data collection period, only one mammography machine is available for the whole country and it was located in Niamey). It was accessible only to few rich women or women referred under specific conditions. In Niger, screening is done using clinical breast examination. Hormone replacement therapy is not also common in Niger. As showed in the descriptive results, only $0.4 \%(0.2-1.3)$ of Niger Women smoke and $0.7 \%(0.3-1.7)$ of them drink alcohol, so even if these are known established risk factors, they don't seem to be very relevant in Niger context, so we did not weigh them. Breastfeeding, maternity, physical activity, breast self-examination, clinical breast examination and age related factors were weighted to account for their relative importance. Some important potential breast cancer symptoms were also weighted (see table below).

In general, women should have half of the overall knowledge score (36) to be labeled aware of breast cancer.

Table 1: Knowledge score construction: KAP Survey Breast Cancer - Niger 2018, Women 


\begin{tabular}{l|l|l|l|l}
\hline Knowledge of symptoms & Yes & I dont know-no & weighting & Score \\
\hline - Change in the position of your nipple & 1 & 0 & no & 1 \\
- Pulling in off your nipple & 1 & 0 & no & 1 \\
\hline - Pain in one of your breasts or armpits & 1 & 0 & yes & 2 \\
\hline - Puckering or dimpling of your breast skin & 1 & 0 & no & 1 \\
\hline - Discharge or bleeding from your nipple & 1 & 0 & no & 1 \\
\hline - Nipple rash & 1 & 0 & no & 1 \\
\hline - Redness of your breast skin & 1 & 0 & no & 1 \\
\hline - Change in the size of your breast or nipple & 1 & 0 & yes & 2 \\
\hline - Change in the shape of your breast or nipple & 1 & 0 & yes & 2 \\
\hline - A lump or thickening in your breast & 1 & 0 & yes & 2 \\
\hline - A lump or thickening under your armpit & 1 & 0 & yes & 2 \\
\hline maximum weighted score for symptoms & & & & $\mathbf{1 6}$
\end{tabular}

maximum weighted score for symptoms

Knowledge of risk and protective factors

- Alcohol intake

- Smoking (chewing tobacco)

- Nulliparity and late maternity

- Physical inactivity and obesity

- Breastfeeding

- Early maternity

- Balanced diet and lifestyle

-Age

maximum weighted score for risk and protective factors

\begin{tabular}{llll}
1 & 0 & no & 1 \\
1 & 0 & no & 1 \\
1 & 0 & yes & 3 \\
1 & 0 & yes & 2 \\
1 & 0 & yes & 3 \\
1 & 0 & yes & 2 \\
1 & 0 & no & 1 \\
1 & 0 & yes & 2 \\
\hline & & & $\mathbf{1 5}$
\end{tabular}

Knowledge of Breast cancer good practice

Breast self-exam (once a week or a month)

Clinical examination (Yes or No)

Mammography (Yes or No)

1
1
1

yes

yes

no

2

yes 2

(1)

maximum weighted score good practice

5

Overall maximum knowledge score

36

(symptoms + risk and protective factors + good practice)

\section{3: Generalized Linear Model}

A Generalized Linear Model was built where knowledge score was used as a response variable to assess its relationship with other predictors related to socio demographic, practice and attitude features. The response variable, knowledge score, was used to classify women based on their answers into those aware of breast cancer (was coded as response variable $=1$ ) and those not aware (was coded as response variable $=0$ ). A generalized linear model through Ordinary Logistic Regression, OLR (ignoring clustering) 
and through Generalized Estimating Equations (GEE) (Liang and Zeger 1986; Verbeke and Molenberghs, 2005), accounting for clustering at health center levels were used to model the odds of being aware of breast cancer accounting for predictors.

\section{Results}

\section{1: Description of the sample:}

The questionnaire was administered by 675 women in the two regions historically hosting national reference hospitals, Niamey and Zinder. Niamey is the capital city and Zinder the most populated region in Niger. Households were selected within health districts in 'commune 2", "commune 3" and "commune 4" in Niamey region and Goure, Miriah and Zinder in Zinder region (see sampling frame in list of annexes).

Average age of women that participated to the survey was 39.2 years (38.2-40.3), 79.1\% (75.9-82.0) of them were married and 46.5\% (42.8-50.3) from rural areas. Moreover, $48.4 \%$ (44.7-52.2) were not educated, only 5.5\% (4.0-7.5) have higher education. Average number of children per woman was 4.6 (4.37-4.82). Average age of menarche was 14.15 years (13.98 - 14.32). Hausa remains the main ethnic group (53\%) followed by Djerma (17\%). 96.9\% were Muslim, and 2.7\% Christian. 43\% (39.7-47.2) of the survey participants were 'house women' or jobless while $20 \%$ (17.2-23.2) were vendors. Only $0.4 \%(0.2-1.3)$ of the respondents smoke and $0.7 \%(0.3-1.7)$ drink alcohol.75.6\% (72.2-78.6) of the interviewed women have a breastfeeding attitude with 31\% (26.9-55.2) doing exclusive breastfeeding. 42.2\% (38.6-46.0) of women adopt oral contraception and 35.5\% (32.2-39.4) do not practice contraception at all. Finally, 28.3 \% (24.9-31.9) had an abortion history.

\subsection{Overall knowledge of breast cancer}

Table 2 : Women's overall knowledge of breast cancer

\begin{tabular}{|c|c|c|c|c|c|}
\hline $\begin{array}{l}\text { Women's } \\
\text { knowledge } \\
\text { breast cancer }\end{array}$ & of & $\begin{array}{l}\text { Overall knowledge \% } \\
-(95 \% \mathrm{CI})\end{array}$ & $\begin{array}{l}\text { Knowledge of } \\
\text { symptoms }\end{array}$ & $\begin{array}{l}\text { Knowledge of risk and } \\
\text { protection factors }\end{array}$ & $\begin{array}{l}\text { Knowledge of } \\
\text { good practice }\end{array}$ \\
\hline Aware & & $41.6 \quad(37.8-45.4)$ & $\begin{array}{l}65.0(61.3- \\
68.7)\end{array}$ & $27.4 \quad(24.0-31.0)$ & $16.9(14.2-19.7)$ \\
\hline Not aware & & $58.4(54.6-62.2)$ & $\begin{array}{l}35.0 \\
38.7)\end{array}$ & $72.6 \quad(69.0-76.0)$ & $83.1 \quad(80.3-85.8)$ \\
\hline
\end{tabular}


We can see from table 3 that overall women's knowledge of breast cancer is low, only $41.6 \%$ (37.8-45.4) were aware of breast cancer following the retained definition (cf. knowledge score construction in methodology section). In the paragraphs below, we further discuss each dimension of breast cancer knowledge.

\subsection{Women's knowledge of breast risk and protective factors}

Overall women's knowledge of breast cancer risk and protective factors remains very poor, it only reached $27.4 \%$ (24.0-31.0). For instance, Table 4 shows the responses of women regarding 5-likert scale items related to breast cancer risk factors. Only 25.5\% (22.4-29.2) of the interviewed women strongly agree that alcohol intake is a risk factor for breast cancer with $14.7 \%(12-17.4)$ simply agree, in total $40.2 \%$ recognize alcohol intake as a breast cancer risk factor. $26.2 \%$ (23.1-29.3) agree that smoking is a risk factor for breast cancer with $29.8 \%$ (26.4-33.3) strongly agree reaching a total of $56 \%$ of women that see smoking as a breast cancer risk factor. Only 11.6\% (9.3-14.1) of women strongly agree that nulliparity and late maternity are breast cancer risk factors with $18.1 \%$ (15.3-21) that simply agree which is a total of only $29.7 \%$ of women that recognizes these risk factors. Only $27.3 \%$ agree that physical inactivity and obesity could be a risk factor for breast cancer.

Table 3: breast cancer risk factors

\begin{tabular}{|c|c|c|c|c|c|}
\hline Risk factors & $\begin{array}{l}\text { Strongly disagree } \\
\%-(95 \% \mathrm{CI})\end{array}$ & $\begin{array}{l}\text { Disagree(\%) } \\
-95 \% \text { CI }\end{array}$ & $\begin{array}{l}\text { Neither agree nor } \\
\text { disagree (\%) - 95\% CI }\end{array}$ & $\begin{array}{l}\text { Agree(\%) - } \\
95 \% \text { CI }\end{array}$ & $\begin{array}{l}\text { Strongly } \\
\text { agree(\%) - 95\% } \\
\text { CI }\end{array}$ \\
\hline Alcohol intake & $19.3(16.3-22.6)$ & $\begin{array}{l}18.5 \\
21.7)\end{array}$ & $22(19-25.2)$ & $\begin{array}{l}14.7 \\
17.4)\end{array}$ & $\begin{array}{l}25.5(22.4- \\
29.2)\end{array}$ \\
\hline Smoking & $12.6(10.1-15.3)$ & $\begin{array}{l}11(8.6- \\
13.3)\end{array}$ & 20.4 (17.2-23.7) & $\begin{array}{l}26.2 \\
(23.1- \\
29.3)\end{array}$ & $\begin{array}{l}29.8 \\
33.3)\end{array}$ \\
\hline $\begin{array}{l}\text { Nulliparity and } \\
\text { late maternity }\end{array}$ & $20.6 \quad(17.6-23.6)$ & $\begin{array}{l}21.6 \\
24.9)\end{array}$ & $28.1 \quad(25-31.4)$ & $\begin{array}{l}18.1 \\
(15.3-21)\end{array}$ & $11.6(9.3-14.1)$ \\
\hline $\begin{array}{l}\text { Physical inactivity } \\
\text { and obesity }\end{array}$ & $16.3(13.6-19.1)$ & $\begin{array}{l}23(20.2- \\
26)\end{array}$ & $33.4 \quad(29.7-37.1)$ & $\begin{array}{l}13.5(11- \\
16)\end{array}$ & $\begin{array}{l}13.8(11.1- \\
16.5)\end{array}$ \\
\hline
\end{tabular}


We can see from Table 5 that only 21.2\% (18.1-24.3) strongly agree that early maternity can protect against breast cancer with $14.4 \%(12-17.3)$ that simply agree with is a total of $35.6 \%$ that recognizes early maternity as a protective factor. Up to $10.7 \%$ (8.3-12.9) strongly disagree that breastfeeding can protect against breast cancer. 15\% (12.1-17.8) strongly disagree that a balanced diet and lifestyle can protect them against breast cancer, with $20.9 \%$ (17.6-23.9) that simply disagree, whereas a total of 35.9\% of women don't see a balanced diet and lifestyle as a protective factor. These figures also correlate with the low knowledge of risk factors denoting a lack of sufficient knowledge of breast cancer protective factors.

Table 4: breast cancer protective factors

\begin{tabular}{|c|c|c|c|c|c|}
\hline $\begin{array}{l}\text { Protective } \\
\text { factors }\end{array}$ & $\begin{array}{l}\text { strongly disagree } \\
\%-(95 \% \mathrm{CI})\end{array}$ & $\begin{array}{l}\text { Disagree(\%) } \\
-95 \% \text { CI }\end{array}$ & $\begin{array}{l}\text { Neither agree nor } \\
\text { disagree }(\%)-95 \% \text { CI }\end{array}$ & $\begin{array}{l}\text { Agree(\%) - } \\
95 \% \text { CI }\end{array}$ & $\begin{array}{l}\text { Strongly } \\
\text { agree(\%) - 95\% } \\
\text { CI }\end{array}$ \\
\hline Breastfeeding & $10.7(8.3-12.9)$ & $\begin{array}{l}21.2(18.2- \\
24.3)\end{array}$ & $23.4(20.2-26.7)$ & $\begin{array}{l}20.9 \\
(17.9-24.1)\end{array}$ & $23.9(20.7-27.4)$ \\
\hline Early maternity & $10.5(8.3-13)$ & $\begin{array}{l}23.6(20.6- \\
26.7)\end{array}$ & $30.4 \quad(27-33.6)$ & $\begin{array}{l}14.4 \\
17.3)\end{array}$ & $21.2(18.1-24.3)$ \\
\hline $\begin{array}{l}\text { Balanced diet } \\
\text { and lifestyle }\end{array}$ & $15(12.1-17.8)$ & $\begin{array}{l}20.9(17.6- \\
23.9)\end{array}$ & $21.9(18.5-25)$ & $\begin{array}{l}17(14.2- \\
20)\end{array}$ & $25.2(21.9-28.4)$ \\
\hline
\end{tabular}

Only $36.2 \%$ of the interviewed women are convinced that long term survival (longer than 5 years) is common when breast cancer is treated in an early stage.

\subsection{Women's knowledge of breast cancer warning signs}

Table 5 : Breast cancer warning signs 


\begin{tabular}{|c|c|c|c|}
\hline Breast cancer warning signs & Yes & No & I don't know \\
\hline Change in the position of your nipple: & $65.8(62.2-69.6)$ & $25.9(22.5-29.5)$ & $8.3(6.2-10.4)$ \\
\hline Pulling in off your nipple & $48.9(44.7-52.4)$ & $39.9(36.4-44.0)$ & $11.3(9.0-13.8)$ \\
\hline Pain in one of your breasts or armpit & $66.3(62.8-70.2)$ & $24.3(21.1-27.6)$ & $9.3(7.1-11.6)$ \\
\hline Puckering or dimpling of your breast skin & $46.4(42.6-50.3)$ & $39.1(35.6-42.9)$ & $14.4(11.8-17.3)$ \\
\hline Discharge or bleeding from your nipple: & $61.8(61.8-65.6)$ & $28.0(28.0-31.4)$ & $10.2(10.2-12.6)$ \\
\hline A lump or thickening in your breast & $60.1 \quad(56.2-64.1)$ & $27.1 \quad(23.4-30.4)$ & $12.8(10.3-15.6)$ \\
\hline Nipple rash & $52.2 \quad(48.1-55.7)$ & $33.9 \quad(30.6-37.7)$ & $14.0(11.4-16.9)$ \\
\hline "Redness" of your breast skin & $62.1(58.1-65.6)$ & $27.7(24.4-31.3)$ & $10.1(7.7-12.5)$ \\
\hline A lump or thickening under your armpit & $64.5(61-68.4)$ & $26.7(23-30.4)$ & $8.8(6.7-11)$ \\
\hline Change in the size of your breast or nipple & $58.1(54.4-62.2)$ & $30.2(26.8-33.8)$ & $11.7(9.3-14.3)$ \\
\hline Change in the shape of your breast or nipple & $57.8(54.1-61.6)$ & $29.4(26.3-32.9)$ & $12.7(10.3-15.4)$ \\
\hline
\end{tabular}

The majority of Niger Women consider change of size 58.1\% (54.4-62.2) and shape $57.8 \%$ (54.1-61.6) of their breast as a warning sign for breast cancer. Change in the position of the nipple is considered as a warning sign by $65.8 \%(62.2-69.6)$ of women. Pain in one of your breasts or armpit was considered a symptom by 66.3\% (62.8-70.2), discharge or bleeding from your nipple by 61.8\% (61.8-65.6). "Redness" of your breast skin (adapted in this context as "Change in colored aspect of the skin") was considered as a symptom by $62.1 \%$ (58.1-65.6) and 'A lump or thickening under your armpit' by $64.5 \%$ (61-68.4). Pulling in of your nipple 48.9\% (44.7-52.4), puckering or dimpling of your breast skin 46.4 \% (42.6-50.3) and 'nipple rash' 52.2\% (48.1-55.7) were not considered by a (borderline) majority of women as breast cancer warnings signs. In general, women had an overall acceptable level of knowledge of breast cancer symptoms 65\% (61.3-68.7), anyhow, a higher level of knowledge was demonstrated here compared to the one regarding risk and protective factors.

\subsection{Breast examination, mammography and history of screening participation:}

We found that $32.7 \%(29.3-36.4)$ of the interviewed women practice breast selfexamination, with $53.4 \%$ of these (48-60.6) practicing it rarely, 23.1\% (17.6 - 29) at least every 6 months, $16.3 \%$ (11.8 - 21.7) every month and only 6.3\% practice every week (3.29.5). Only $25.2 \%$ (22.1-28.6) of women had participated in breast cancer screening in the past, $65.2 \%$ (61.5-68.7) intend to participate to breast cancer screening in the future. In Niger, very often screening is done through clinical breast examination. Main reasons for not participating in breast cancer screening include lack of facilities or hospital in the area 
20.9\% (15.3-26.4) and lack of money (transport) 34.9\% (28.5-47.1). Nevertheless 8.5\% (5.111.9) of the interviewed women declare not to participate to breast cancer screening because the doctor is a man.93.8\% (91.7-95.4) of women declare to go to the doctor once facing breast cancer symptoms. Moreover, 2.2\% (1.4-3.6) goes to a traditional healer and 3.3\% declare consulting their family as first reaction when confronted with breast cancer symptoms.If we consider the knowledge of breast cancer good practice as defined earlier (breast examination, clinical breast examination, mammography), only 16.9\% (14.2-19.7) of women can be classified as being aware of breast cancer good practice.

\section{Factors associated with knowledge of breast cancer:}

Table 7 shows the results of modeling of odds of being breast cancer aware given socio demographic and specific predictors. We fitted both OLR and GEE models.

Table 6: Generalized linear model results: Being aware of breast cancer (OLR and GEE)

\begin{tabular}{|c|c|c|c|c|}
\hline Risk factors & $\begin{array}{l}\text { Logistic reg B coef- (P- } \\
\text { value) }\end{array}$ & $\begin{array}{l}\text { Adjusted OR- (95\% } \\
\text { CI) }\end{array}$ & $\begin{array}{l}\text { Adjusted OR P- } \\
\text { value }\end{array}$ & $\begin{array}{l}\text { Coef GEE\% - }(95 \% \\
\text { CI })\end{array}$ \\
\hline Intercept & $0.32(0.80)$ & & & $0.62(0.715)$ \\
\hline Age & $-0.02(0.008)$ & $0.98(0.96-0.99)$ & 0.008 & $0.98(0.055)$ \\
\hline Menstrual age & $0.09(0.98)$ & $\begin{array}{l}1.11(0.99- \\
1.22)\end{array}$ & 0.085 & $1.03(0.448)$ \\
\hline race & $-0.04(0.75)$ & $0.99(0.51-1.91)$ & 0.989 & $0.83(0.579)$ \\
\hline Zone (urban-rural) & $-1.242(<0.001)$ & $0.29(0.20-0.44)$ & $<0.001$ & $0.34(<0.001)$ \\
\hline Children number & $0.03(0.37)$ & $1.04(0.96-1.12)$ & 0.377 & $1.09 \quad(0.740)$ \\
\hline Breastfeeding practice & $-0.39(<0.08)$ & $0.68(0.44-1.05)$ & $<0.08$ & $1.17 \quad(0.540)$ \\
\hline $\begin{array}{l}\text { Exclusive } \\
\text { breastfeeding }\end{array}$ & 1.20. $(<0.001)$ & $3.34(2.12-5.26)$ & $<0.001$ & $1.34 \quad(0.135)$ \\
\hline $\begin{array}{l}\text { Breast self- } \\
\text { examination }\end{array}$ & $-0.09(0.60)$ & $0.90(0.60-1.36)$ & 0.671 & $1.20(0.550)$ \\
\hline $\begin{array}{l}\text { Clinical breast } \\
\text { examination }\end{array}$ & $0.71(<0.001)$ & $2.04(1.31-3.16)$ & 0.003 & $2.25(<0.001)$ \\
\hline $\begin{array}{l}\text { Breast cancer } \\
\text { screening }\end{array}$ & $-0.64(0.004)$ & $0.53(0.34-0.82)$ & 0.004 & $0.87 \quad(0.517)$ \\
\hline Other screening & $-0.30(0.51)$ & $0.74(0.30-1.84)$ & 0.521 & $1.30(0.582)$ \\
\hline
\end{tabular}

Hosmer and Lemeshow goodness of fit (GOF) test: $X^{2}=20, \mathrm{df}=8, \mathrm{p}$-value $=0.007$

Considering OLS, we found the odds of being aware of breast cancer associated with age, breastfeeding practice, clinical breast examination, area, and participation to breast cancer screening. In fact, the odds of being aware of breast cancer is 3 times higher for a woman 
doing exclusive breastfeeding as compared to one who does not. The odds of being aware of breast cancer of women doing clinical breast examination is twice that of a woman who is not doing clinical breast examination. Women that have participated to breast cancer screening are half as likely to be aware of breast cancer compared to those who don't participate. Younger women are more likely to be aware of breast cancer compared to older ones. Women living in urban areas are less likely to be aware of breast cancer compared to those living in rural areas. Considering GEE results, thus accounting for within health center clustering, we found the following results. Niger women that consult in the same health center are more likely to see the same health professionals and receive the same awareness programs. Clinical breast examination, age and zone were found to be associated with breast cancer knowledge. The odds of a woman that practices clinical breast examination is 2.25 higher than of one who is not. Urban women were less likely to be aware of breast cancer as compared to rural women. Younger women were more likely to be aware of breast cancer. We observed an association between knowledge of breast cancer good practice and number of children, women with more children were more likely to be aware of breast cancer good practice.

\section{Discussion}

Although the knowledge score was constructed somehow like a composite multidimensional score, overall women's knowledge of breast cancer in Niger was found to be low. Dimensions where women showed specific low levels are knowledge of breast cancer risk/protective factors and knowledge of "good practice" with respectively $27.4 \%$ (24.0-31.0) and $16.9 \%$ (14.2-19.7). In fact, only $23.6 \%$ agree that smoking is a risk factor and $37.8 \%$ see alcohol as a breast cancer risk factor. These proportions could be explained by the insignificant proportion of women who smoke or drink in the sample survey which is representative of the Niger community in general due to religious and personal beliefs. Only $39.3 \%$ and $42.2 \%$ respectively see physical inactivity and nulliparity as a breast cancer risk factor.

These findings correspond with those of Azubuike SO; 2017 who recently found a generally poor knowledge of breast cancer among women in Benin city, Nigeria, whose knowledge concerning breast cancer risk factors was also worse than concerning signs and symptoms. Okobia MN et al.; 2006 in a study in Nigeria also found participants to have a poor knowledge of breast cancer with a mean knowledge score of only 42.3\%. Moreover, Kohler RE et al.; 2017 in a study in Malawi also found that women know more about breast cancer symptoms than about breast cancer risk factors like in our study findings. Opeku Y et al.; 2012 observed a low level of breast cancer knowledge within the women 
population in Ghana. A recent literature review on "Symptom awareness measures for breast and cervical cancer in Sub-Saharan Africa" conducted by Jennifer N et al.; 2017 summarized studies all reporting a generally low level of breast cancer awareness in the women population in sub-Saharan Africa.

Only $27.0 \%(23.8-30.4)$ of Niger women have reported to practice clinical breast exam with a general practitioner, it should be noted that this was found to be associated with breast cancer knowledge. In fact, breast cancer in Niger is done using clinical breast exam rather than mammography which is not available and widely accessible in the country. $32.7 \%$ (29.3-36.4) of women reported to practice breast self-exam. While breast self-examination is important, the meta-analysis conducted by AK Hackshaw and EA Paul, 2003 in Russia and China showed its low impact on mortality. 79.6\% of women have never had a mammography (76.3-82.4) which is only available at central level. 3.7\% (2.4-5.3) of women participated in HIV and cervical cancer screening in the past.

We found women living in urban and peri urban areas to be less likely to be aware of breast cancer compared to those living in rural areas. Niamey being the capital city, almost all women consult a doctor in an urban health center though these are administratively conceived to be rural contrasting the recent urbanization phenomena. Ann Muthoni and Ann Neville Miller; 2010 revealed a difference between rural and urban Kenyan women's knowledge and attitudes regarding breast cancer and breast cancer early detection measures in a qualitative study. In fact, urban middle-income women were more informed about breast cancer risk factors and early detection measures as compared to other groups including urban low income and rural low-income women. Women with history of participation to breast cancer screening are half likely to be aware of breast cancer compared to those who don't participate, this is surprising, may be women who know less on breast cancer are the ones more motivated to participate to screening.

Educational level was not found to be associated with breast cancer awareness. It should be noted that in the general women population, educational level in Niger is not that much heterogenous, in our sample only $5.5 \%$ have higher education. Lydia $\mathrm{A}$ et al; 2017 could not find an association nor between educational level neither between age on the one hand and breast cancer awareness on the other hand in a study in Limpopo, South Africa. Nevertheless, some studies established an association between breast cancer awareness and educational level in sub Saharan African context in Nigeria (Okobia et al; 2006) and in Ghana (Y. Opoku et al; 2012). We found age to be associated with breast cancer awareness with younger women having more awareness than older ones, in line with findings by Allam and Abd Elaziz 2012. It should be noted that in our survey, only women from 25 years and older were selected to participate to the survey.

\section{Limitations:}

The limitation of this study could find its root in the fact that it was conducted in the two regions of Zinder and Niamey, which historically host national reference hospitals. The study could therefore contain bias in terms of reproducibility in the whole country. Results need to be interpreted within the regions framework. Lack of wide access to equipment of mammography could introduce a bias in the 
proportion of women reporting having undergone a mammography, as during the period of the survey (January 2018), only one mammography machine was available in the whole country which is located in the capital city.

\section{Policy recommendations:}

- Focus breast cancer awareness programs on knowledge of breast cancer risk/protective factors and breast cancer good practice as these are areas of which women know the least.

- Support the implementation of cancer national policy in the country with support of WHO

- Awareness programs should target different age classes but focus on older women

- Design a strategy to shift from a clincial breast to a mammography screening program in Niger

- Provide and decentralise mammography units and build mutilateral partnerships to support women to have financial access to breast cancer screening.

- Design a stategy to encourage women to participate in breast cancer screening

\section{Conclusion}

Niger women were found to have a relatively low level of breast cancer awareness. Knowledge of risk/protective factors and breast cancer good practice were main factors downscaling this knowledge. Meanwhile women's knowledge of breast cancer symptoms appeared to be acceptable. Clinical breast examination, age, area of residence, breastfeeding and history of participation in breast cancer screening were found to be associated with breast cancer knowledge using OLR. Using GEE, only clinical breast examination, age and area of residence were found to be associated with overall breast cancer knowledge.

This study reported an overview of Niger's women knowledge of breast cancer and can contribute in guiding awareness program for screening/early detection. Awareness programs in Niger should promote clinical breast examination as mammography is not common and target older women both in rural and urban areas with focus on breast cancer risk/protection factors. Participation to breast cancer screening should be encouraged.

\section{List Of Abbreviations}

BCAM: Breast Cancer Awareness Measure

Cl: Confidence interval

$D F$ : Degree of freedom

$D E R$ : "Direction des études et Recherches"

DEP: "Direction des études et de la planification" 
GEE : Generalized estimating Equations

GLM : Generalised Linear Model

KAP: Knowledge, Attitudes and Practice

$\mathrm{MOH}$ : Ministry of health

NA nor DA: Neither Agree nor Disagree

$O L R$ : Ordinary Logistic Regression

OR: Odds Ration

SPSS: Statistical Package for Social Sciences

SG: "Secrétariat Général"

REM-Africa : Références Etudes de Marches en Afrique

WHO: Word Health Organization

\section{Declarations}

Ethics approval and consent to participate

The study was approved by Niger republic ministry health by authorization of directorate of research and studies, DER (Direction des etudes et Recherche), reference letter: 04712/MSP/SG/DEP/DER on 21-122017). The results are expected to contribute in strengthening the disease knowledge and scientific literature in the country. Each respondent was asked to decide whether she wants to participate to the survey after an explanation and oral informed consent was obtained before proceeding.

\section{Consent for publication : Not applicable}

\section{Availability of data and materials}

The datasets used and/or analysed during the current study are available from the corresponding author on reasonable request.

\section{Competing interests}

The authors declare that they have no competing interests

\section{Funding}

This study was funded by myself as PhD student while working for Medecins Sans Frontieres, Doctors without Borders as country director for the NGO in Democratic Republic of Congo. I funded the data 
collection team (training) and transport) to the study site.

I will request for a waiver as a Niger Republic citizen, my country being part of LMIC

\section{Authors' contributions}

AA analyzed the data, reported the figures and drafted the first study materials (questionnaire, methods, data plan). He participated on the field to data collection

$\mathrm{GH}$ advise on the questionnaire and study design. He gave significant guidance on the current scientific literature state on the topic globally.

ID advised on the knowledge score construction in Niger context and supported with the current state of existing scientific literate on the topic at local level. She advise on the questionnaire desing also.

All authors read and approved the final manuscript

\section{Acknowledgment:}

We thank the Niger ministry of health ("Sécretariat Géneral"), the surgery service in Niamey national Hospital through Dr Dile Issimouha and Gazobi reference center for their support to this study. We thank all the doctors and nurses head of services that welcomed the data collection teams.

\section{Authors' information}

1. AA is a PhD student at Department of epidemiology and social medicine, university of Antwerp, he holds a BSc in Statistics and an MSc in Biostatistics from Hasselt university, Belgium

2. GH is a professor at Department of epidemiology and social medicine, university of Antwerp, Belgium, His expertise includes substance use and misuse in different groups, such as minors, students, elderly people, arrestees and sex workers, cancer screening (breast, colorectal, lung and cervical cancer) and health promotion. He has co-authored over 100 A1 publications.

3. ID is a medical doctor specialised in oncologist surgery, she is working in Niamey National Reference Hospital. She is the president of SOS Cancer Niger and very active in the organisation of breast cancer screening

\section{References}

Allam MF, et al. J Prev Med Hzg. 2012 Dec,53 (4):195-8.

Anderson, B. O. \& Jakesz, R. Breast Cancer Issues in Developing Countries: An Overview of the Breast Health Global Initiative World J Surg (2008) 32: 2578. https://doi.org/10.1007/s00268-007-9454-Z

Ann Muthoni and Ann Neville Miller, 2010, An Exploration of Rural and Urban Kenyan Women's Knowledge and Attitudes Regarding Breast Cancer and Breast Cancer Early Detection Measures. 
Altman DG (1991) Practical statistics for medical research. London: Chapman and Hall)

A. Trupe, Lydia \& Rositch, Anne \& Dickerson, Lindsay \& Lucas, Su \& C. Harvey, Susan. (2017). Knowledge and Attitudes About Breast Cancer in Limpopo, South Africa. Journal of Global Oncology. 3. JG0.2016.008102. 10.1200/JG0.2016.008102.

Azubuike SO. Breast cancer risk factors and signs: How much do Nigerian women know?.. Int J Adv Med Health Res 2017;4:40-3

Brinton LA1, Figueroa JD, Awuah B, Yarney J, Wiafe S, Wood SN, Ansong D, Nyarko K, Wiafe-Addai B, Clegg-Lamptey JN. (2014), "Breast cancer in Sub-Saharan Africa: opportunities for prevention". Breast Cancer Res Treat. 2014 Apr;144(3):467-78. doi: 10.1007/s10549-014-2868-z. Epub 2014 Mar 7.

Campbell I (2007) 'Chi-squared and Fisher-Irwin tests of two-by-two tables with small sample recommendations". Statistics in Medicine 26:3661-3675

Colditz GA, Bohlke K (2014). "Priorities for the primary prevention of breast cancer". CA Cancer J Clin 2014; 64: 186-194.

DeVellis RF (2003). "Scale development: theory and applications". $2^{\text {nd }}$ ed. Thousand Oaks, CA: Sage Publishing; 2003., online, 27-11-2016

Ferlay J, Shin HR, Bray F, Forman D, Mathers C, Parkin DM. "Estimates of worldwide burden of cancer in 2008": GLOBOCAN 2008. Int J Cancer. 2010;127:2893-2917. [PubMed]

Glaros, A. and Kline, R. (1988). "Understanding the accuracy of tests with cutting scores: The sensitivity, specificity, and predictive value model". Journal of Clinical Psychology, 44, 1013-1023.

Globocan: $h$ ttp://globocan.iarc.fr/old/burden.asp?selection_pop $=142562 \& T e x t-p=$ Niger\&selection_cancer $=3152 \&$ Text $-\mathrm{c}=$ Breast\&pYear $=3 \&$ type $=0 \&$ window $=1 \&$ submit $=$ Execute

Graham Colditz, Kari Bohlke (2015) "Preventing breast cancer now by acting on what we already know."' npj Breast Cancer 1, Article number: 15009 (2015) doi:10.1038/npjbcancer.2015.9

Hattie, John \& Cooksey, Ray. (1984). ' 'Procedures for Assessing the Validities of Tests Using the "KnownGroups" Method". Applied Psychological Measurement - APPL PSYCHOL MEAS. 8. 295-305. $10.1177 / 014662168400800306$.

Jennifer N. Githaigaa, Fiona Walterb, Suzanne Scottc, Amos Mwakad, Jennifer Moodleya (2017), 'Symptom awareness measures for breast and cervical cancer in Sub-Saharan Africa: A literature review", http://www.cansa.org.za/files/2017/12/Poster-Symptom-awareness-measures-for-breast-and-cervicalcancer-in-Sub-Saharan-Africa.pdf

J Glob Oncol. 2017 Apr 21;3(5):480-489. doi: 10.1200/JG0.2016.005371. eCollection 2017 Oct. 
Breast Cancer Knowledge, Behaviors, and Preferences in Malawi: Implications for Early Detection Interventions From a Discrete Choice Experiment.

Kline, R. (1999). [Review of Psychometric theory, Nunnally and Bernstien, (1994).] Journal of Psychoeducational Assessment, 17, 275-280.

Kohler RE, Gopal S, Lee CN, Weiner BJ, Reeve BB, Wheeler SB. Breast Cancer Knowledge, Behaviors, and Preferences in Malawi: Implications for Early Detection Interventions From a Discrete Choice Experiment. J Glob Oncol. 2017;3(5):480-489. Published 2017 Apr 21. doi:10.1200/JG0.2016.005371

Molenberghs, G. and Verbeke, G. (2005). Models for Discrete Longitudinal Data. New York: Springer.

Linsell L, Forbes LJL, Burgess C, Kapari M, Thurnham A, Ramirez AJ (2010). "Validation of a measurement tool to assess awareness of breast cancer". Eur J Cancer. 2010;46(8):1374-1381. doi: 10.1016/j.ejca.2010.02.034. [PubMed] [Cross Ref]

Lord, F. and Novick, M. (1968). 'Statistical theories of mental test scores". Reading, MA: Addison-Wesley.

Nouhou H; Mahamadou H ; Zaki H; Djibo H "Registre des cancers du Niger Données d'enregistrement de 19 ans de fonctionnement (1992-2010) "

Nunnally J. and Bernstein I. (1994). Psychometric Theory, 3rd edn. New York: McGraw-Hill.

Okobia MN, Bunker $\mathrm{CH}$, Okonofua FE, Osime U. Knowledge, attitude and practice of Nigerian women towards breast cancer: a cross-sectional study. World J Surg Oncol. 2006;4:11. Published 2006 Feb 21. doi:10.1186/1477-7819-4-11

-Rating the Risk Factors for Breast Cancer https://www.ncbi.n/m.nih.gov/pmc/articles/PMC1514477/, http://www.who.int/cancer/detection/breastcancer/en/index2.htm/

Ray W Cooksey, John Hattie "Procedures for Assessing the Validities of Tests Using the "Known-Groups" Method, Applied Psychological Measurement July 1984 8: 295-305, doi: 10.1177/014662168400800306 Applied

Richardson JTE (2011) "The analysis of 2 x 2 contingency tables - Yet again". Statistics in Medicine 30:890

Soliman, A. S., et al. (2015) "Epidemiologic and Clinical Profiles of Breast Diseases in Niger".. (2015) Intl J Cancer Oncol 2(2): 1- 6 .

S Mamoudou Garba, H Hami, H Mahamadou Zaki, ' 'Profil épidémiologique et anatomopathologique du cancer du sein au Niger", 2013

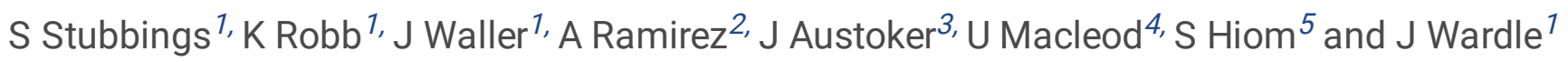


(2009), "'Development of a measurement tool to assess public awareness of cancer", British Journal of Cancer (2009) 101, S13-S17. doi:10.1038/sj.bjc.6605385 www.bjcancer.com

Unicef, at a glance: Niger, 2012, accessed on 24-10-2015,

ttp://www.unicef.org/infobycountry/niger_statistics.htm/

Vlayen, Hellings, Claes, Abdou, \& Schrooten, (2015); ' 'Measuring Safety Culture in Belgian Psychiatric Hospitals: Validation of the Dutch and French Translations of the Hospital Survey on Patient Safety Culture"', March 2015, DOI:10.1097/01.pra.0000462605.17725.48

Wachira, J., Busakhala, A., Chite, F., Naanyu, V., Kisuya, J., Otieno, G., Keter, A., Mwangi, A. and Inui, T. (2017). ' 'Refining a questionnaire to assess breast cancer knowledge and barriers to screening in Kenya: Psychometric assessment of the BCAM".BMC Health Services Research, 17(1).

WHO, Cancer Country Profiles, 2014, http://www.who.int/cancer/country-profiles/ner_en.pdf?ua = 1, accessed on 22-07-2018

World Health Organization (WHO). World Cancer Report. Stewart B, Kleihues P (eds.) International Agency for Research on Cancer; 2003

Y. Opoku, "Knowledge, attitudes, beliefs, behaviour and breast cancer screening practices in Ghana, West Africa,"Pan African Medical Journal, vol. 11, p. 28, 2012

Zaki, H. M., Garba-Bouda, O., Garba, S. M., et al. (2013) "Profil épidémiologique et anatomopathologique du cancer du sein au Niger". (2013) Journal Africain du Cancer / African Journal of Cancer 5(4): 185191.

\section{Supplementary Files}

This is a list of supplementary files associated with this preprint. Click to download.

- Annexes.docx 